\title{
DISPERSION STRENGTHENED SHEET ALLOYS FOR EXHAUST COMPONENT APPLICATIONS
}

\author{
R. Darolia and J. R. Dobbs* \\ GE Aircraft Engines, 1 Neumann Way, Cincinnati, Ohio 45215 \\ *GE Corporate Research Center, Schenectady, New York 12301
}

\begin{abstract}
The development and properties of a new class of high-temperature shect alloys are described in this paper. The alloys utilize rapid solidification processing and the dispersion strengthening concept in a $\mathrm{Ni}$-base superalloy composition to achieve excellent hightemperature stress rupture properties. The proccssing, compositions, microstructures, physical and mechanical properties as well as component fabrication are discussed.

\section{Introduction}

Rapid solidification plasma deposition from alloy powders is an attractive processing approach for making thin section superalloy parts operating in the 1600 to $1800^{\circ} \mathrm{F}$ temperature range. In this process, parts are made by incrementally solidifying molten powder particles on a mandrel to form parts of essentially simple geometries. Several modifications of this approach have been evaluated for the past decade (1). Rapid solidification plasma deposition (RSPD) and spray forming, commonly referred to as the Osprey process are two more commonly used processes. The process is particularly suitable when it is difficult to cast large thin section parts, or when subsequent processing is not possible or desirable. Composition homogeneity as well as higher strengthener concentration in the alloy are two other benefits derivable from rapid solidification. A fine grain microstructure (typical grain size 25 to $60 \mu \mathrm{m}$ ) is an inherent attribute of such a process. The fine grain structure provides several advantages as well as disadvantages. The main advantage of the fine grain size is that it can provide high tensile strengths based on the Hall Petch relationship. However, the major disadvantage is poor high-temperature stress rupture and creep properties which do not compare well with those of the cast superalloys of similar compositions. Due to the presence of a small amount of oxides in the deposits, it is difficult to grow grains to an appreciable size to improve high-temperature creep properties. Therefore, an alloy development program was carried out to improve creep and rupture properties by creating a dispersion of stable particles in the matrix as well as at the grain boundaries. Many types of dispersoids, such as $\mathrm{Y}_{2} \mathrm{O}_{3}, \mathrm{Al}_{2} \mathrm{O}_{3}$ and carbides were evaluated. The oxide dispersoids were found to be very inhomogeneously dispersed. In addition, alloys containing the oxide dispersoids had poor room temperature ductility and showed no improvement in high-temperature strength. Eutectic carbide dispcrsoids, principally $\mathrm{TaC}$ in the form of platelets and spheroids, were found to be effective strengtheners, resulting in alloys with rupture properties superior to the currently used sheet superalloys such as René 41, HS 188 and Hastelloy X.

\section{Processing}

The rapidly solidified plasma deposition (RSPD) process is generally carried out in a low vacuum, inert gas atmosphere chamber. Powder particles of a specified composition are fed into a high energy plasma flame, where they are melted to form droplets of liquid. The plasma flame directs the stream of droplets against a heated mandrel/substrate where they impact and rapidly solidify and adhere to the mandrel. The temperature of the mandrel is kept low enough to cause the droplets to freeze as soon they come in contact with the mandrel. The droplets typically flatten as they impact the mandrel. The desired deposit thickness is incrementally built up. The as-deposited densities are sufficiently high such that post deposition heat treatments are normally adequate to achieve near theoretical density. Near-net shapes can be formed by proper selection of the mandrel configuration and clever translation and rotation of the plasma gun and the mandrel. Deposition rates are high enough that the process is economically feasible. A schematic of the process is shown in Figure 1.

The deposit is removed from the mandrel which is generally made of a low alloy steel by chemically leaching, machining or mechanical separation. Because of the very rapid solidification rates (estimated to be about $10^{7 \circ} \mathrm{F} / \mathrm{sec}$ ), a non-equilibrium microstructure is obtained. The deposits are heat treated to obtain an equilibrium structure.

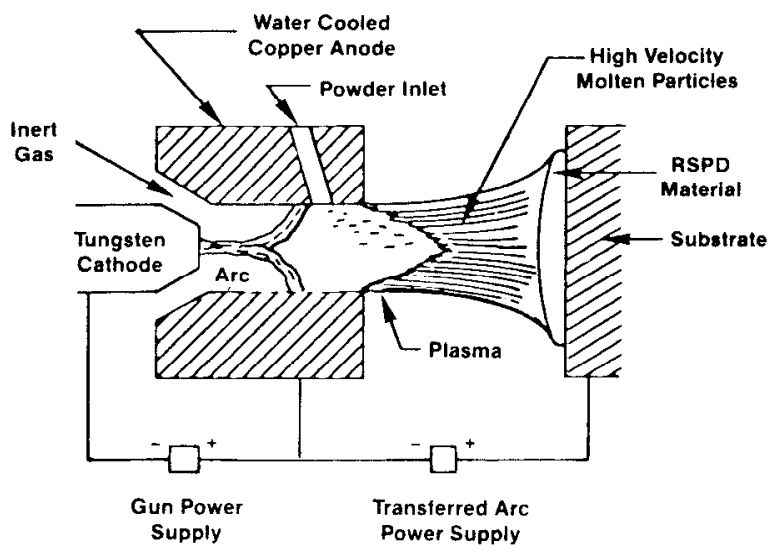

Figure 1. Schematic of a plasma spray process. 
Another variation of this incremental solidification process is often called spray forming. The principles of spray forming differ from the RSPD processing only to the extent that the droplets of liquid are formed directly from the melt, rather than remelting powder particles. There is essentially no difference in the resulting microstructures from the two processes, and the mechanical properties are also identical. This paper describes the properties of alloys processed by the RSPD process. The properties of the spray formed material were also evaluated and found to be identical to those of the RSPD processed material.

There is a wide range of parameters under which acceptable alloy deposits can be made. Typical RSPD processing parameters are:

Plasma gun power

Mandrel pre-heat tempcrature

Deposition chamber pressure

Powder feed rate

Gun to workpiece distance

Primary gas - argon

Secondary gas - helium

Carrier gas

Powder size

Powder particles of the specified alloy compositions are generally obtained by argon atomization. Based on poor mechanical properties of the plasma sprayed deposits containing oxides, particular emphasis was placed on obtaining powders with low oxygen levels. Oxygen level was specified at below $300 \mathrm{wppm}$.

\section{Composition. Heat treatment and Microstructure}

The initial work on the carbide dispersion strengthened alloy system identified an alloy designated RD-8A as the most promising alloy (2). The nominal composition of this alloy is shown in Table 1 . This composition was based on earlier alloy development work on directionally solidified (DS) NiTaC alloys such as NiTaC-14B (3. 4). The alloy is essentially a gamma prime strengthened Ni-base superalloy which has been further strengthened by precipitation of $\mathrm{TaC}$ platelets and spheroids by an eutectoid reaction. The asdeposited microstructure does not contain these dispersoids. These dispersoids were found to significantly improve the rupture properties of the alloy.
Processing, microstructure, and properties of the RD-8A alloy were extensively evaluated. About forty composition variations of the RD-8A alloy which included $\mathrm{C}$. Ta, AI, Mo, Re, $\mathrm{Nb}, \mathrm{Co}, \mathrm{Ti}, \mathrm{W}$ and $\mathrm{Hf}$ were also evaluated. Selected composition variations are shown in Table 1. For each alloy, the composition variation is highlighted in bold in Table 1. The effect of these alloying variations on microstructure, especially carbide morphology and mechanical properties, will be discussed later in a separate section in this paper. The majority of the paper describes the microstructure and properties of the RD-8A alloy of the nominal composition.

As was mentioned earlier, the as-deposited microstructure does not contain dispersoids. A heat treatment schedule was developed to precipitate the dispersoids as well as to optimize their morphology. A typical heat treatment for the RSPD deposits consisted of $2100^{\circ} \mathrm{F}$ for 6 hours (for carbide precipitation), followed by $2400^{\circ} \mathrm{F}$ for 4 hours (for gamma prime solution), and followed by $1975^{\circ} \mathrm{F}$ for 16 hours and $1650^{\circ} \mathrm{F}$ for 16 hours (for gamma prime precipitation). The carbide platelets which were precipitated at $2100^{\circ} \mathrm{F}$ were stable at the $2400^{\circ} \mathrm{F}$ solution temperature, which was used to fully solution $\gamma$ which subsequently precipitated during the 1975 and $1650^{\circ} \mathrm{F}$ aging treatments. An as-deposited microstructure of the RD-8A alloy is shown in Figure 2. The as-deposited microstructure does not show any dispersoids.

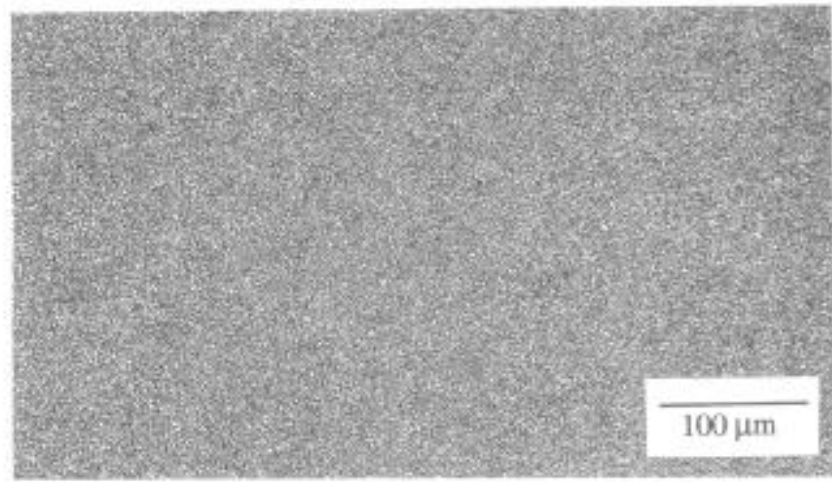

Figure 2. As-deposited microstructure of RD-8A alloy.

Table 1 Compositions of selected RD-8A alloys (in weight \%). The alloys are arranged to show a systematic variation (typed in bold) in selected alloying elements.

\begin{tabular}{|c|c|c|c|c|c|c|c|c|c|c|c|c|}
\hline Alloy & Al & $\mathrm{Cr}$ & $\mathrm{Co}$ & Mo & W & $\mathrm{Re}$ & $\mathrm{Ta}$ & C & $\bar{B}$ & $Y$ & Hf & $\mathrm{Ni}$ \\
\hline RD-8A & 5.5 & 4.2 & 4.0 & 3.2 & 4.5 & 6.8 & 8.4 & 0.23 & 0.03 & 0.05 & & $\mathrm{Bal}$ \\
\hline RD-8A-I & 5.2 & 4.2 & 4.0 & 3.2 & 4.5 & 6.8 & 8.4 & 0.23 & 0.03 & 0.05 & & $\mathrm{BaI}$ \\
\hline RD-8A.P & 6.0 & 4.2 & 4.0 & 3.2 & 4.5 & 6.8 & 8.4 & 0.23 & 0.03 & 0.05 & & $\mathrm{Bal}$ \\
\hline RD-8A-M & 5.5 & 4.2 & 4.0 & 3.2 & 4.5 & 6.8 & 8.4 & 0.12 & 0.03 & 0.05 & & $\mathrm{Bal}$ \\
\hline RD-8A-44 & 5.5 & 4.2 & 4.0 & 3.2 & 4.5 & 6.8 & 8.4 & 0.19 & 0.03 & 0.05 & & $\mathrm{Bal}$ \\
\hline RD-8A-N & 5.5 & 4.2 & 4.0 & 3,2 & 4.5 & 6.8 & 8.4 & 0.30 & 0.03 & 0.05 & & Bal \\
\hline RD-8A-T & 5.5 & 4.2 & 4.0 & 3.2 & 4.5 & 6.8 & 8.4 & 0.30 & 0.03 & 0.05 & $4.4 \mathrm{~V}$ & $\mathrm{Bal}$ \\
\hline RD-8A-S & 5.5 & 4.2 & 4.0 & 3.2 & 4.5 & 6.8 & 9.5 & 0.23 & 0.03 & 0.05 & & $\mathrm{BaI}$ \\
\hline RD-8A-45 & 5.5 & 4.2 & 4.0 & 3.2 & 4.5 & 6.8 & 8.4 & 0.23 & 0.03 & 0.05 & 0.10 & $\mathrm{Bal}$ \\
\hline RD-8A-42 & 5.5 & 4,2 & 4,0 & 4.0 & 4.5 & 6.8 & 8.4 & 0.23 & 0.03 & 0.05 & & Bal \\
\hline RD-8A-U & 5.5 & 4.2 & 4.0 & 4.0 & 4.5 & 6.8 & 8.4 & 0.23 & 0.03 & 0.05 & 0.10 & $\mathrm{Ba}$ \\
\hline RD-8A-33 & 5.5 & 4.2 & 4.0 & 1.0 & 4.5 & 6.8 & 8.4 & 0.23 & 0.03 & 0.05 & $0.5 \mathrm{Nb}$ & $\mathrm{Bal}$ \\
\hline RD-8A-35 & 5.5 & 4.2 & 4.0 & 3.2 & 4.5 & 5.0 & 8.4 & 0.23 & 0.03 & 0.05 & $0.5 \mathrm{Nb}$ & $\mathrm{Bal}$ \\
\hline RD-8A-39 & 5.5 & 5.0 & 7.5 & 0.0 & 4.5 & 6.0 & 8.4 & 0.23 & 0.03 & 0.05 & $1.0 \mathrm{TI}$ & Bal \\
\hline RD-8A-40 & 5.5 & 4.2 & 7.5 & 3.2 & 4.5 & 6.8 & 8.4 & 0.23 & 0.03 & 0.05 & & Bal \\
\hline RD-8A-41 & 5.5 & 4.2 & 12.5 & 3.2 & 4.5 & 6.8 & 8.4 & 0,23 & 0.03 & 0.05 & & $\mathrm{Bal}$ \\
\hline RD-8A-43 & 5.5 & 4.2 & 12.5 & 4.0 & 4.5 & 6.8 & 8.4 & 0.23 & 0.03 & 0.05 & & Bal \\
\hline RD-8A-46 & 5.2 & 4.2 & 4.0 & 3.2 & 4.5 & 6.8 & 8.4 & 0.23 & 0.03 & 0.05 & 0.10 & Bal \\
\hline RD-8A-47 & 5.5 & 4.2 & 4.0 & 3.2 & 4.5 & 6.8 & 6.0 & 0.23 & 0.03 & 0.05 & 0.10 & Bal \\
\hline RD-8A-48 & 5.5 & 4.2 & 4.0 & 3.2 & 4.5 & 6.8 & 7.5 & 0.23 & 0.03 & 0.05 & 0.10 & $\mathrm{Bal}$ \\
\hline RD-8A-49 & 5.2 & 4.2 & 12.5 & 4.0 & 4.5 & 5.5 & 8.4 & 0.23 & 0.03 & 0.05 & 0.10 & $\mathrm{BaI}$ \\
\hline
\end{tabular}


The microstructure after the deposit is fully heat treated is shown in Figure 3( $\mathrm{a}$ and b). In these micrographs, the platelet morphology of the dispersoids can be seen. The scanning electron micrographs in Figure 4 show the square morphology of the platelets. The micrographs in Figure 4 were taken after removing the $\gamma+\gamma$ matrix by electrolytic etching. It was also observed that the platelets were dispersed predominantly at the grain boundaries. The electron microprobe analysis established these platelets to be $\mathrm{TaC}$ containing some amount of $\mathrm{Mo}, \mathrm{W}$ and $\mathrm{Re}$. For the purpose of this paper, these earbides will be referred to as TaC carbides. It is important to point out that a more traditional heat treatment schedule of solution and subsequent age typically utilized for Ni-base superalloys can also be used for these RSPD deposits for obtaining microstructures similar to the one shown in Figure 3, except with one exception. The carbide platelets following a traditional superalloy heat treatment cycle were larger in size (carbide length about 25 to $35 \mu \mathrm{m}$ compared to about $17 \mu \mathrm{m}$ for the $2100^{\circ} \mathrm{F}$ treatment). Heat treatments were carried out in flowing argon to avoid formation of a carbide denuded zone in the periphery of the specimens. The carbide morphology was also found to be a strong function of the alloy composition, as will be discussed later.
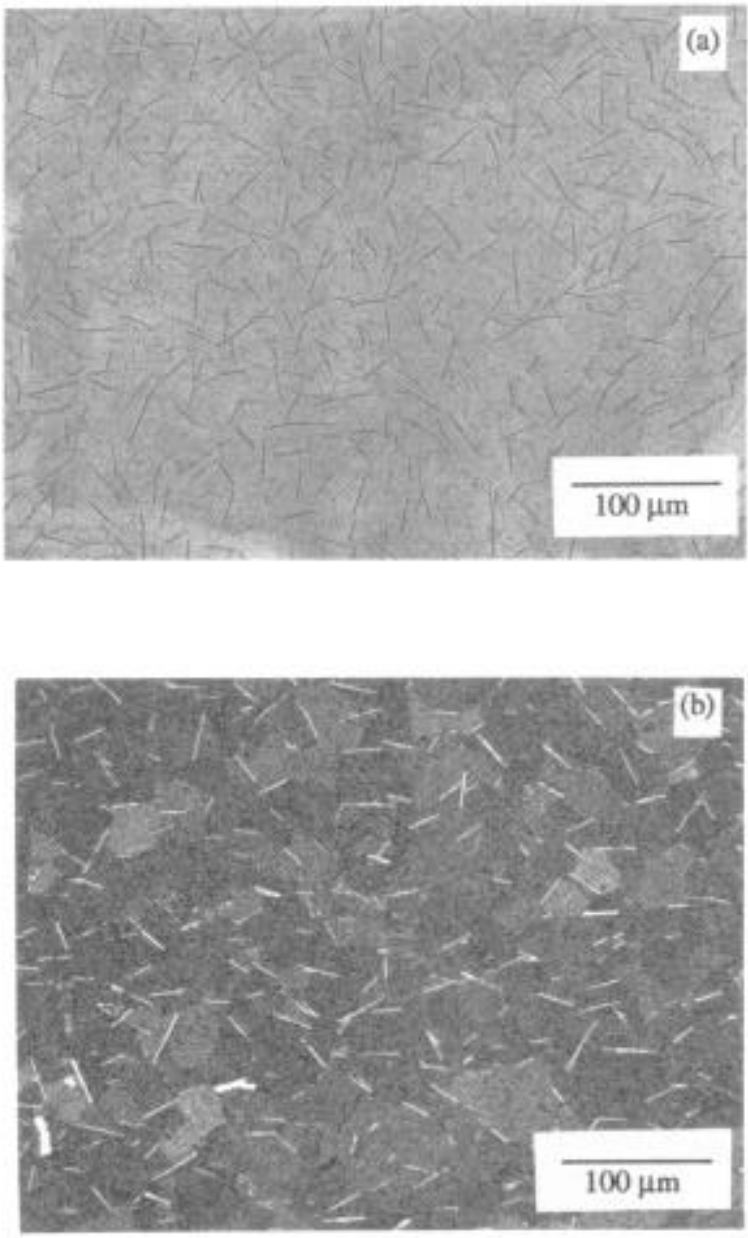

Figure 3. Microstructure of RD-8A alloy after heat treatment, (a) prior to etching, (b) after etching.
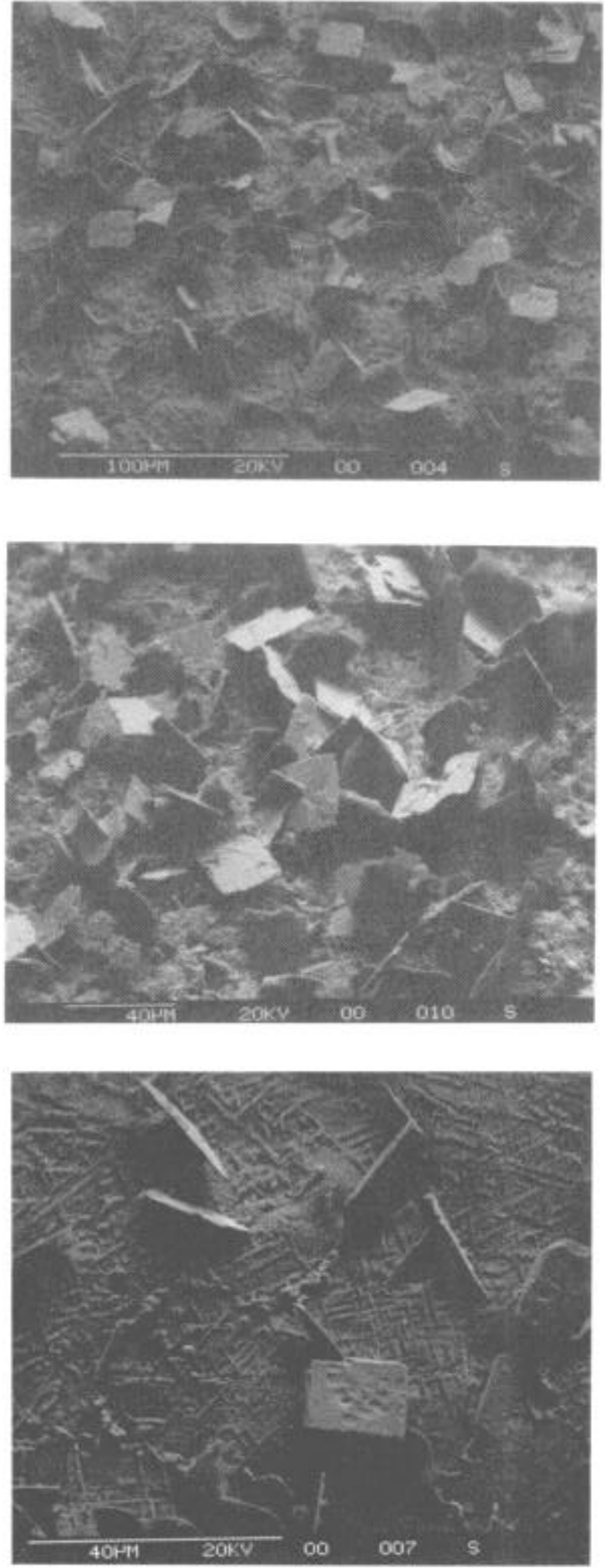

Figure 4. Scanning electron micrographs (three different magnifications) of RD-8A alloy after heat treatment. 


\section{Physical Properties}

The incipient melting temperature of the RD-8A alloy was determined by differential thermal analysis (DTA) to be $2450^{\circ} \mathrm{F}$ which is about $50^{\circ} \mathrm{F}$ higher than the majority of Ni-base superalloys. The density was measured to be $0.328 \mathrm{lb} / \mathrm{in}^{3}$. The mean coefficient of thermal expansion of the alloy RD-8A was measured and compared with several competitive alloys; René 41, HS-188, Hastelloy X, Haynes 214 and Haynes 230. As shown in Figure 5, RD-8A has a substantially lower coefficient of thermal expansion. The coefficient of thermal expansion is an important physical property influencing thermal fatigue behavior of $\mathrm{Ni}$-base superalloys, especially in large thin structures for exhaust applications. A lower coefficient of thermal expansion is desirable to reduce thermal fatigue induced cracking at the 'hot spots'. The lower coefficient of thermal expansion of RD-8A appears to have contributed to the improved thermal fatigue lives demonstrated in several types of laboratory thermal fatigue tests discussed later.

\section{Mechanical Properties}

\section{Tensile Properties}

The $0.2 \%$ yield and ultimate tensile strengths of RD-8A are shown in Figure 6 in which the strengths are compared with three competitive alloys: Rene 41 , Rene 80 and Hastelloy X. Whereas the RD-8A alloy is significantly superior to Hastelloy $X$, it has about 100 to $150^{\circ} \mathrm{F}$ advantage over Rene 41 and Rene 80 at temperatures above $1600^{\circ} \mathrm{F}$. Tensile plastic elongation as a function of temperature is plotted and compared with Rene 41 in Figure 7. There is a ductility minima of about $1 \%$ at $1600^{\circ} \mathrm{F}$. Alloying modifications and the carbide morphology (which was varied by heat treatments and by alloying modifications) were found to influence the tensile properties as discussed in a later section. Alloy modifications were especially directed towards improving the ductility of the alloy. Figure 8 shows plastic elongation as a function of temperature for several selected alloy modifications (compositions shown in Table 1). As can be seen in this figure, ductility was improved by alloy modifications. Highest ductilities were obtained in alloys with higher carbon levels. Several of the high ductility alloys had high-temperature strength properties comparable to RD-8A alloy of the nominal composition (see figure 14. The plastic elongation of these alloys, although adequate for most applications, is still an area of concern (compared to superalloys currently being used) which must be addressed by further alloy modifications and component and engine tests.

\section{Stress Rupturc Propcrtics}

The stress rupture and creep properties were measured at several temperatures of interest. The stress rupture behavior is plotted and compared with René 41 and HS-188 in Figure 9. Rupture properties of RD-8A obtained from two types of specimens are plotted in Figure 9: 20 mil as-deposited and heat treated sheet specimens and 160 mil gage diameter standard bar specimens machined from a thick deposit. The first few mils of the thin, 20 mil RSPD deposit had higher than normal porosity, which led to lower stress rupture lives shown in Figure 9. A subsequent surface finishing step may be required if these lower properties do not meet design requirements. The RD-8A type alloys exhibit about a $200^{\circ} \mathrm{F}$ rupture strength advantage over René 41 and HS 188 , and though not shown in Figure 9, the RD-8A alloy was found to be equivalent to Rene 80 in rupture strength. The alloy was also found to be equivalent to René 80 in creep resistance.

\section{Thermal Fatigue Resistance}

Since the primary mode of failure for the exhaust components is thermal fatigue, thermal fatigue resistance was one of the critical properties evaluated for the RD-8A alloy. Since it is difficult to accurately simulate engine conditions in a laboratory test, five different types of tests with various conditions were run. LCF, LCF (Hold), thermal-mechanical low cycle fatigue (TMLCF, Hold) and TMLCF (Pulse) are standard fatigue tests. The test conditions are noted in Figure 10. In the burner rig test, the RD-8A tubes (1.5 inch in diameter and 40 mil thick wall) were cycled in front of a torch which generated an 1 inch diameter hot spot of about $2000^{\circ} \mathrm{F}$ in the middle of the tube. In this test, Rene 41 specimens failed at 1176 cycles, whereas the RD-8A specimens had an average life of over 4000 cycles. The results from these tests are summarized in Figure 10. Available data on René 41, cast René 80, MA 956 and Hastelloy $\mathrm{X}$ are also shown. In all these tests, except in the hold time LCF test, RD-8A was shown to be superior to these alloys. Two types of LCF tests were conducted at $1800^{\circ} \mathrm{F}$ and a strain range of $0.4 \%$. Two cycles were used: $20 \mathrm{cpm}$ triangular and $1 / 2 \mathrm{cpm}$ with a compressive strain hold. At $20 \mathrm{cpm}$, the fatigue capability of RD-8A was found to be excellent; two specimens ran 18,819 and 18,148 cycles. This was much better than Hastelloy $\mathrm{X}(5,500$ cycles) or cast René $80(3,200)$ at this condition. However, when subjected to the $1 / 2 \mathrm{cpm}$ compressive hold cycle, the life of RD-8A dropped drastically ( 555 and 668 cycles). At this condition, it was found to be inferior to Hastelloy X (1715 cycles), René 41 (1268 cycles) and cast René 80 (2600). Cracks were found to form in RD-

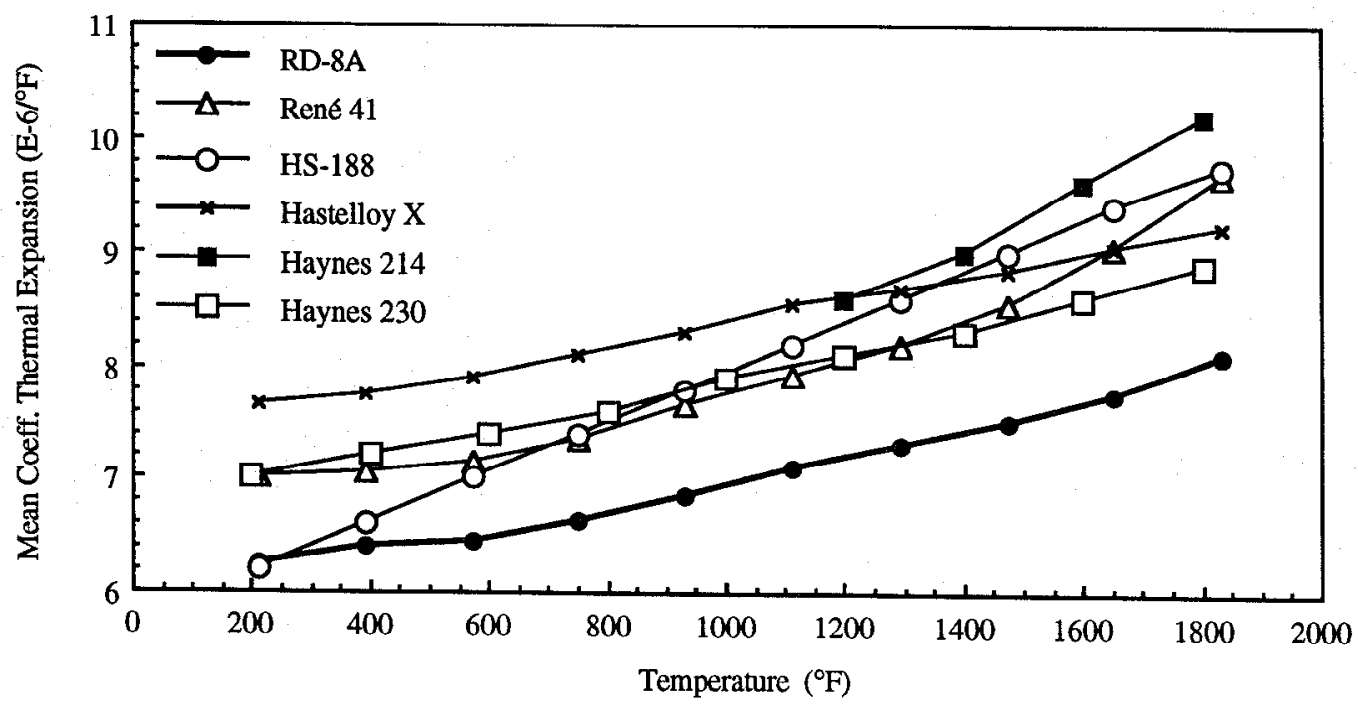

Figure 5. Coefficient of thermal expansion comparison of RD-8A with competitive alloys 

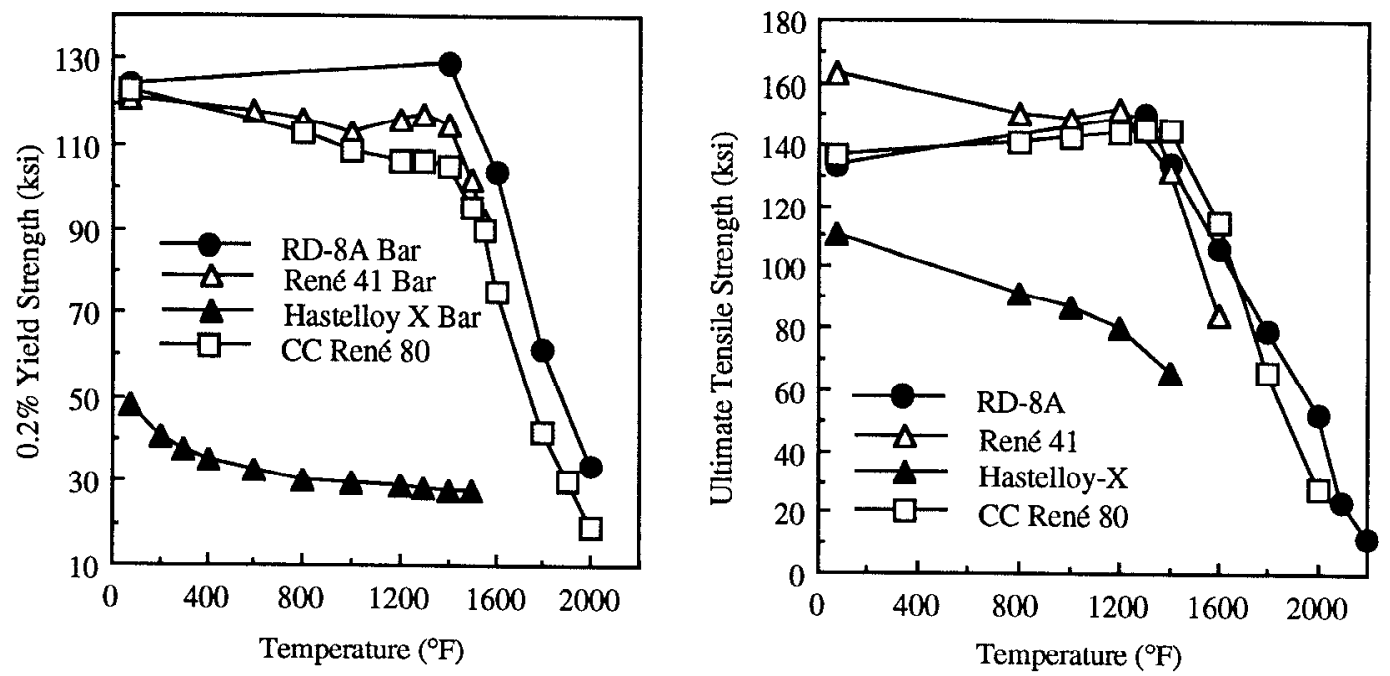

Figure 6. $0.2 \%$ yield strength and ultimate tensile strength of RD-8A as a function of temperature.

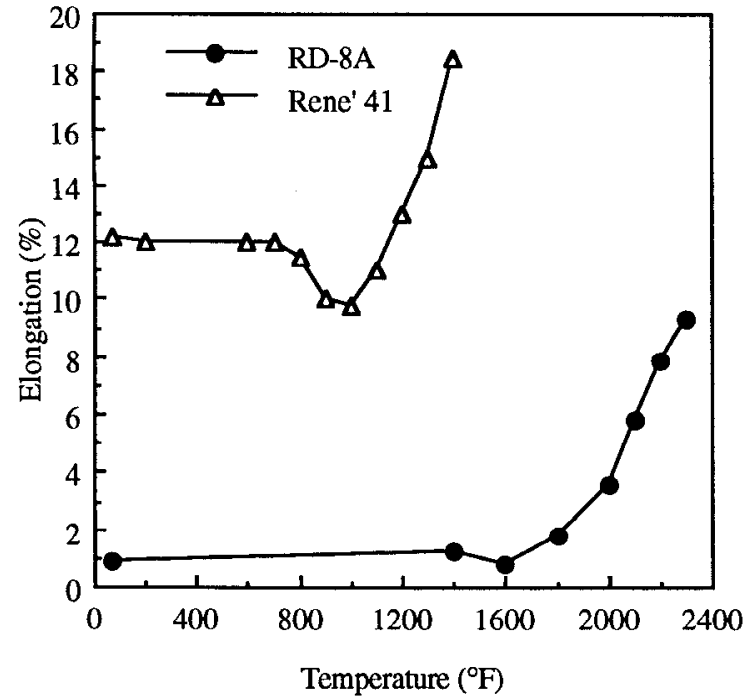

Figure 7. Tensile plastic elongation as function of temperature for RD-8A compared to Rene 41 .

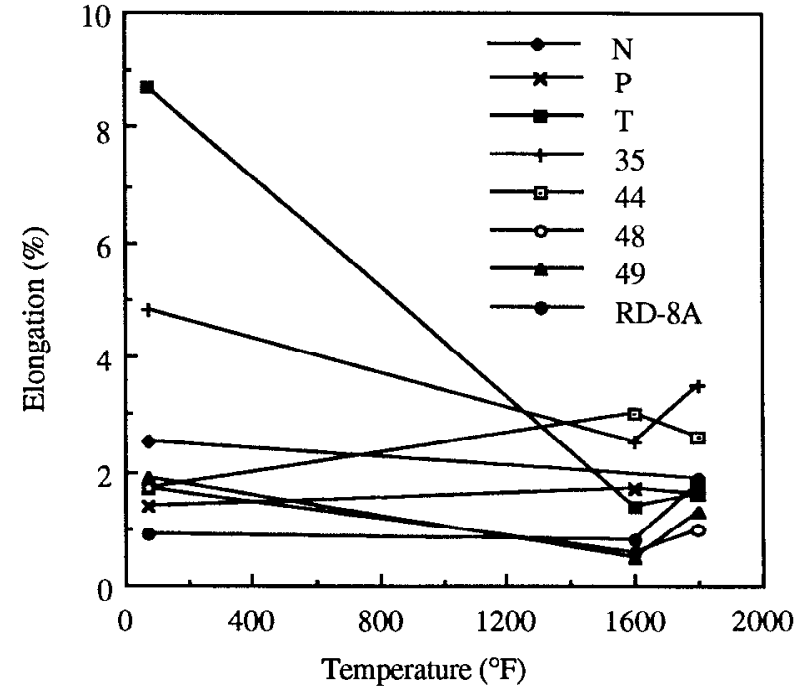

Figure 8. Tensile plastic elongation as a function of temperature for selected alloy modifications.
8A from small blisters which were probably formed by oxidation of the carbide platelets. It appears that, due to the limited ductility of $\mathrm{RD}-8 \mathrm{~A}$, cracks form exposing the $\mathrm{TaC}$ dispersoids to oxidation. However, in the TMLCF hold time testing, RD-8A was found to be superior to René 41 and Hastelloy X.

\section{Oxidation Resistance}

Oxidation pin specimens, 0.25 inch diameter by 3.5 inch long, of the RD-8-A alloy were tested for oxidation resistance in a Mach 1.0 gas velocity oxidation test rig at 2050 and $2150^{\circ} \mathrm{F}$ for up to 200 hours. Each test consisted of 200 cycles of one hour duration out of which the specimens were at the test temperature for 55 minutes. The results are compared with the oxidation behavior of Rene 41, René 80, René 125 and René N5 in Figure 11. The superior oxidation resistance of the RD-8A alloy compared to the conventional superalloys such as René 41, René 80 and René 125 is quite obvious. The oxidation resistance also approaches that of the single crystal alloy René N5 which was especially developed for good oxidation resistance. In the LCF (hold) test, however, oxidation susceptibility of the alloy was observed when a crack is formed due to the limited ductility of the alloy. Cracking of the alloy exposes $\mathrm{TaC}$ dispersoids which appear to have poor oxidation resistance.

\section{Sliding Wear Behavior}

In an application involving sliding wear, the RD-8A alloy was evaluated for wear resistance at $1200^{\circ} \mathrm{F}$, and compared with several competing superalloys. In this test, a René 41 shoe was rubbed against a RD-8A block at 100 lbs load. The RD-8A alloy did not show any wear after 100,000 wear stroke cycles, whereas René 41 had an average wear of 3.1 mils. As shown in Figure 12, the alloy has demonstrated excellent wear resistance. 


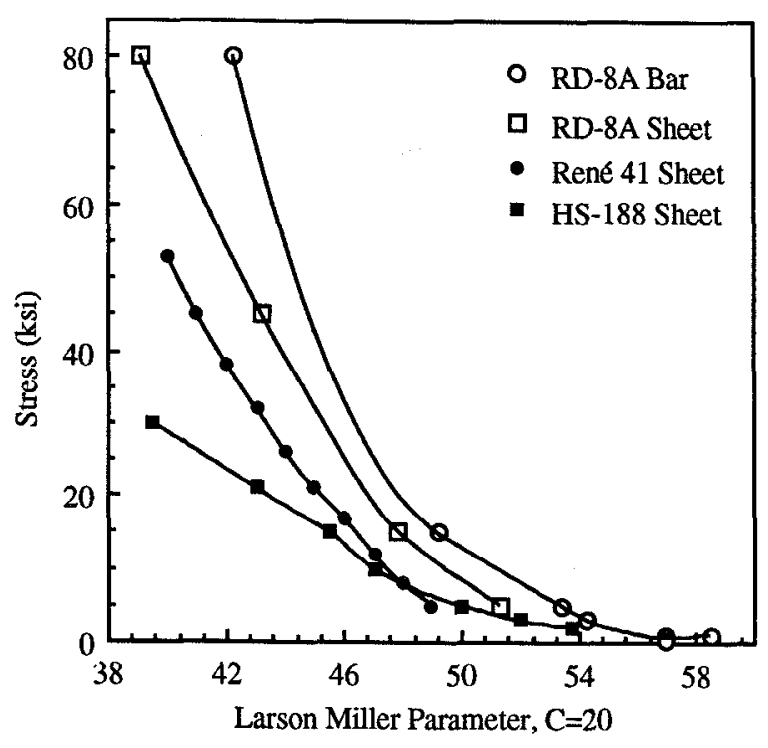

Figure 9. Stress rupture behavior of RD-8A compared with Rene 41 and HS-188.

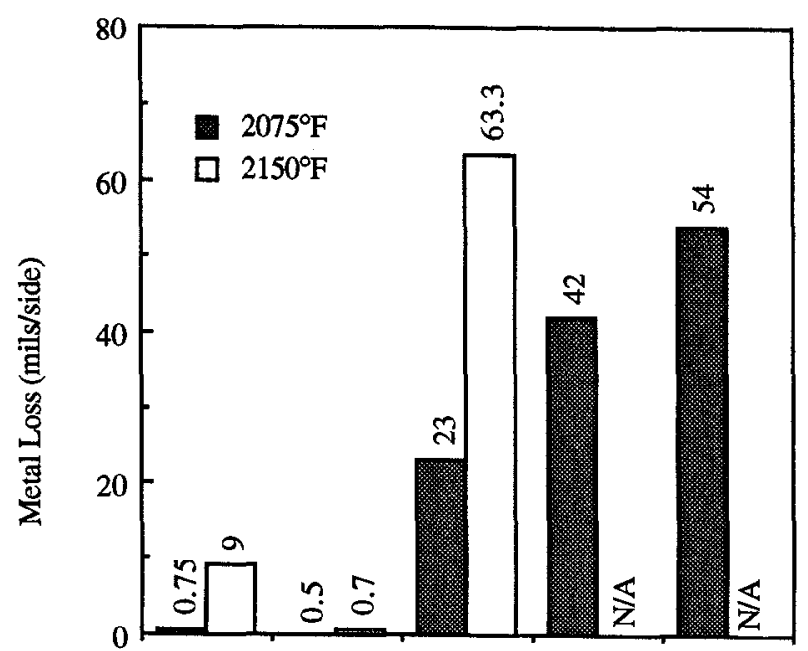

RD-8A Rene' N5 Rene' 125 Rene' 41 Rene' 80 Alloy (uncoated)

Figure 11. Oxidation resistance of RD-8A compared with several Ni-base superalloys.

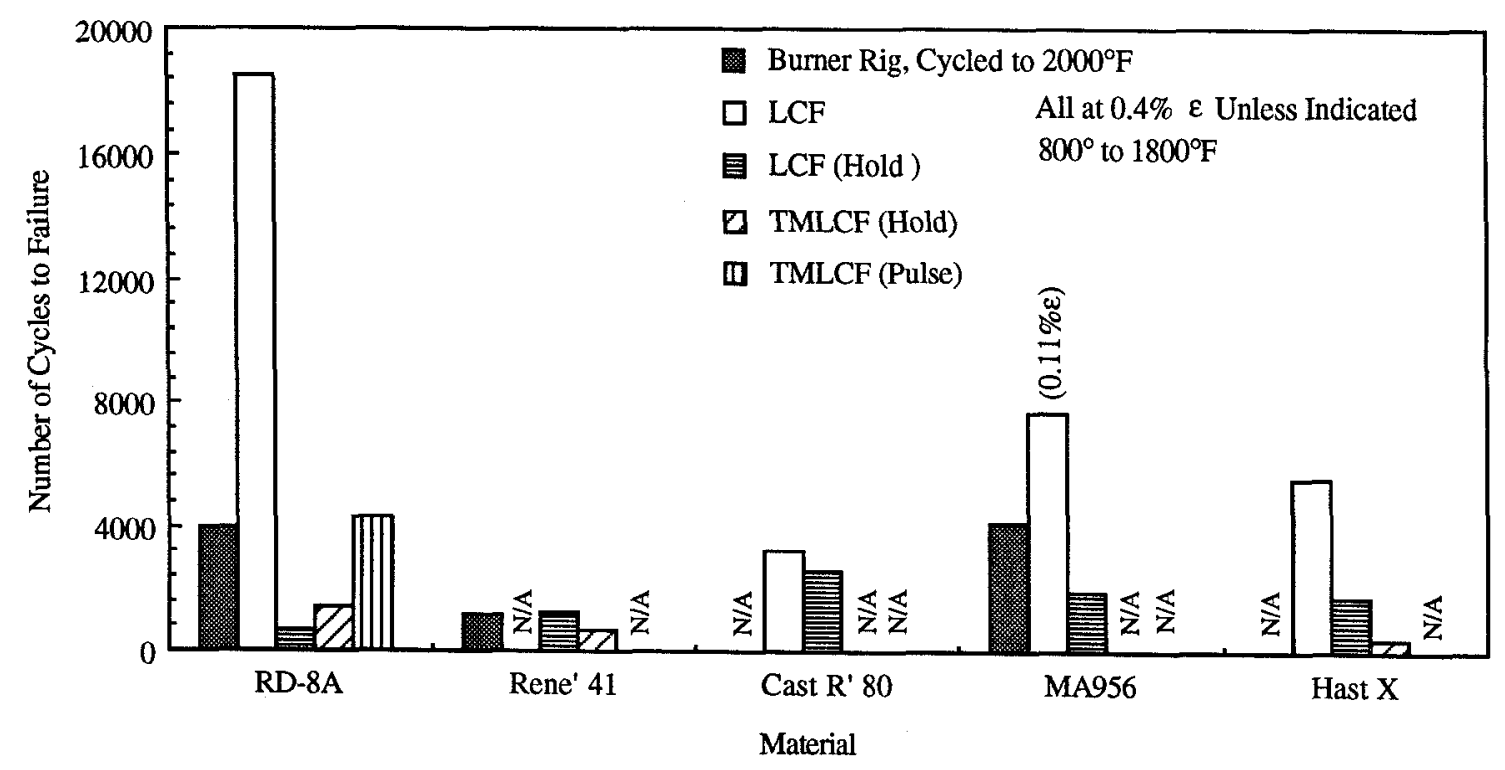

Figure 10. Thermal and low cycle fatigue resistance of RD-8A compared with several superalloys.

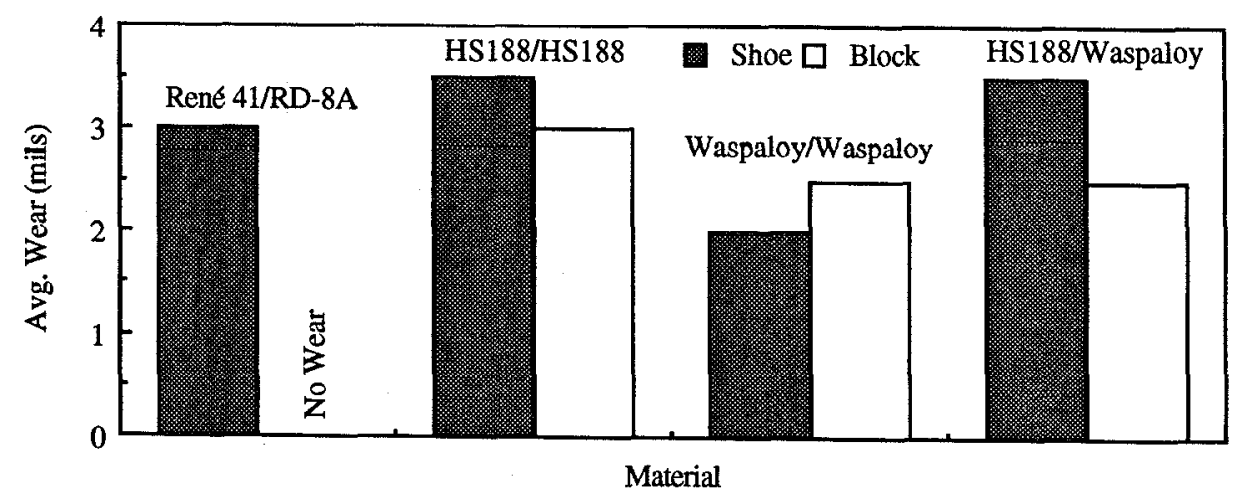

Figure 12. Sliding wear resistance of RD-8A compared with Ni-base superalloys. 


\section{Effect of Compesition Variations on Microstructure and Mechanical Properties}

About forty composition variations were evaluated to determine their effect on the carbide morphology and the mechanical properties. The main emphasis was to improve ductility of the alloy while maintaining high-temperature strength. Due to lack of space, it is not possible to describe in detail the effect of all the variations evaluated. Observations from a small number of selected compositions (shown in Table 1) will be described in this section. Figure 13 shows several representative microstructures with various carbide morphologies. The carbide morphology was found to vary from all platelets to all spheroids, as well as combinations of these two shapes. The spherical carbides formed a necklace structure at the grain boundaries, as clearly seen in Figure 13(a-d). Selected area diffraction in transmission electron microscopy was used to identify the spherical carbides as $\mathrm{TaC}$ carbides. The platelets were

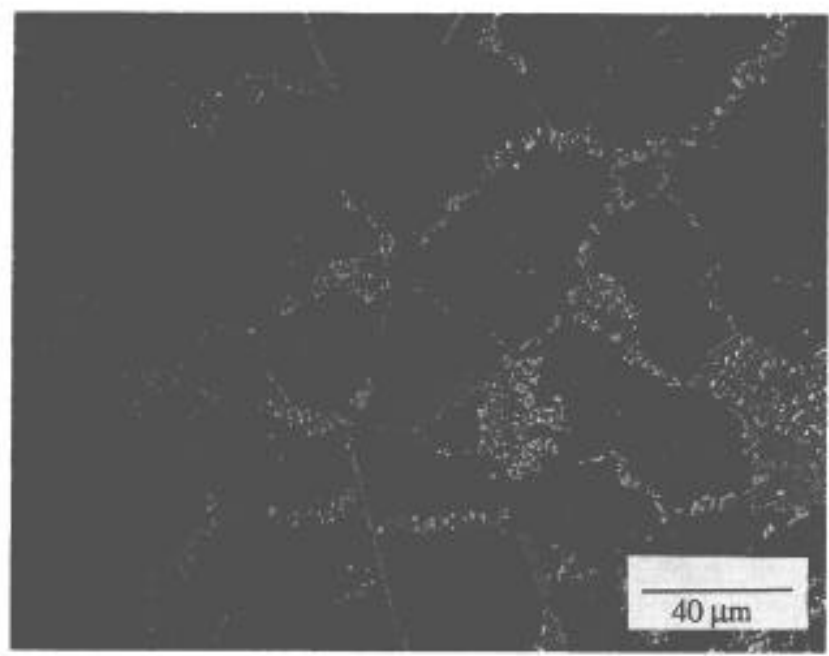

a) $\mathrm{RD}-8 \mathrm{~A}-41$

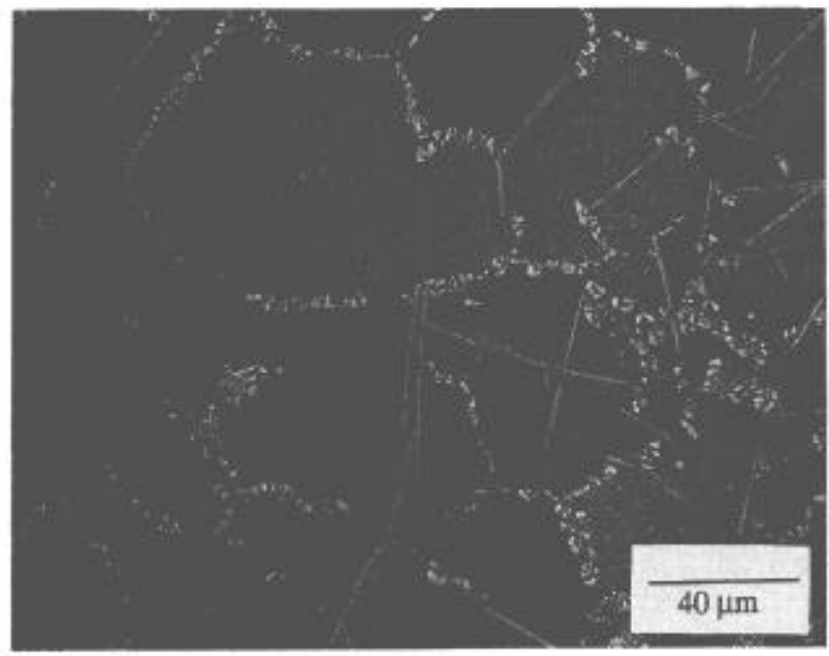

c) $\mathrm{RD}-8 \mathrm{~A}-48$ also identified as MC type (four MC carbides appear to be stacked together to form a tetragonal cell; crystal structure, however, was not clearly identified) carbides mainly containing Ta with varying amounts of $\mathrm{Re}, \mathrm{Mo}$, and $\mathrm{W}$ depending on the alloy composition. Occasionally, M6C carbides were also seen. Depending on the alloy composition, TCP phases were also observed. Mo, $\mathrm{Ta}$ and $\mathrm{C}$ were seen to influence the carbide morphology. As expected, $\mathrm{Al}, \mathrm{Co}, \mathrm{Re}$ and $\mathrm{Ta}$ were found to influence alloy strength and stability.

Stress rupture properties of several representative alloys are shown in Figure 14. The alloy RD-8A-49 was shown to possess the best stress rupture properties. The microstructure of the alloy, as shown in Figure 13(d), consisted entirely of spherical carbides both at the grain boundaries and in the matrix. The tensile ductility of this alloy was slightly better than the baseline RD-8A alloy as shown in Figure 8.

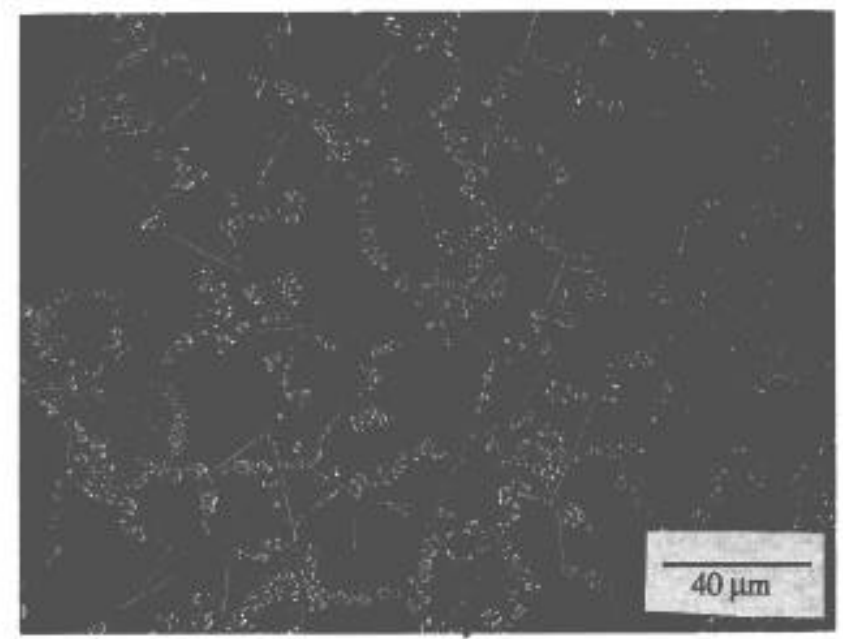

b) $\mathrm{RD}-8 \mathrm{~A}-44$

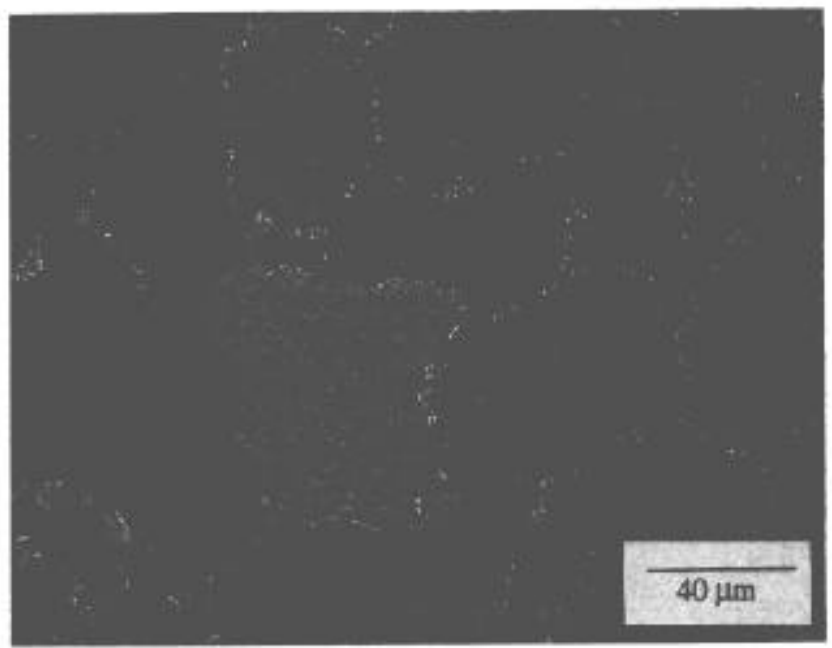

d) RD-8A-49

Figure 13. Optical micrographs showing various carbide morphologies, a) RD-8A-41, b) RD-8A-44, c) RD-8A-48 and d) RD-8A-49. 


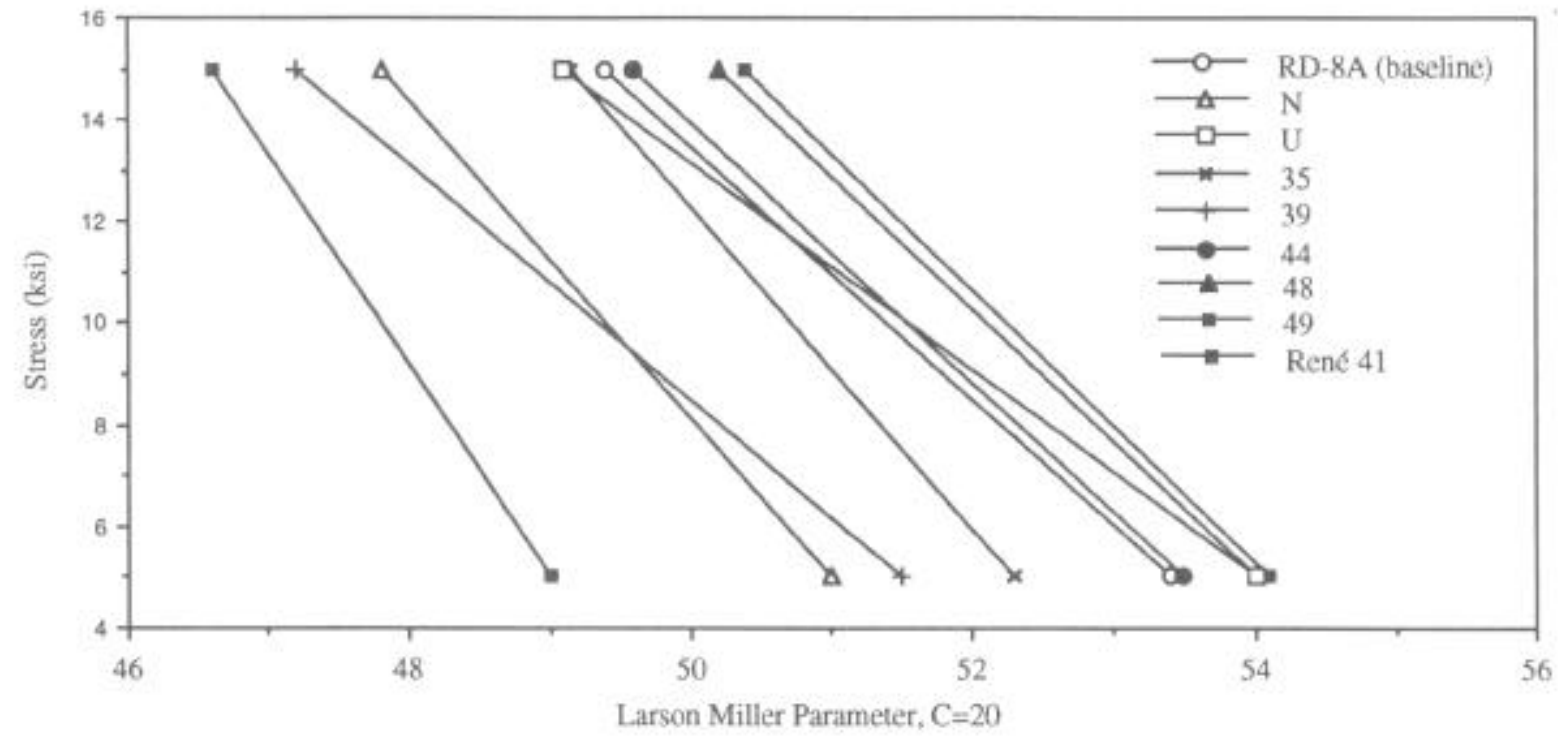

Figure 14. Stress rupture properties of selected alloy modifications.

\section{Component fabrication}

Exhaust parts of various configurations have been made out of the RD -8A alloy utilizing the rapid solidification plasma deposition technique. The deposition was carried out on mandrels of appropriate but simple configurations. After deposition, the mandrels were removed by using nitric acid, leaving free standing parts which were further shaped using hot dies. The hot die forming step to define the second or final shape was carried out at $2100^{\circ} \mathrm{F}$ for six hours. This step combined the forming and the carbide precipitation steps. During the first 15 minutes of this process, the final shape is easily formed because of the low strength of the alloy. After about 15 minutes, the alloy starts to harden due to the formation of the dispersoids and resists further deformation.

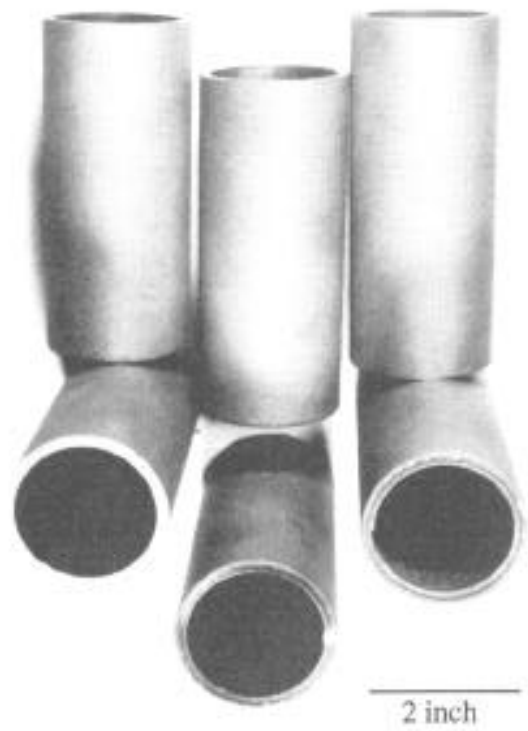

Figure 15(a). Simple tube shapes made out of RD-8A.
Several simple shapes made out of RD-8A are shown in Figure 15. An exhaust divergent seal face sheet made out of RD-8A is shown in Figure 16. This face sheet was fabricated by first depositing a 0.06 inch thick layer on an $8^{\prime \prime}$ diameter tube mandrel made out of a low alloy steel. The steel mandrel was removed by chemical leaching in nitric acid. The free standing tube was then cut open across the width, and straightened and simultaneously formed into the shape shown in Figure 16 by using a BN coated graphite die. All the subsequent heat treatments were done while the part was still in the die to prevent any warpage. Another exhaust component made entirely out of RD-8A by a combination of die forming and brazing various RD-8A parts is shown in Figure 17.
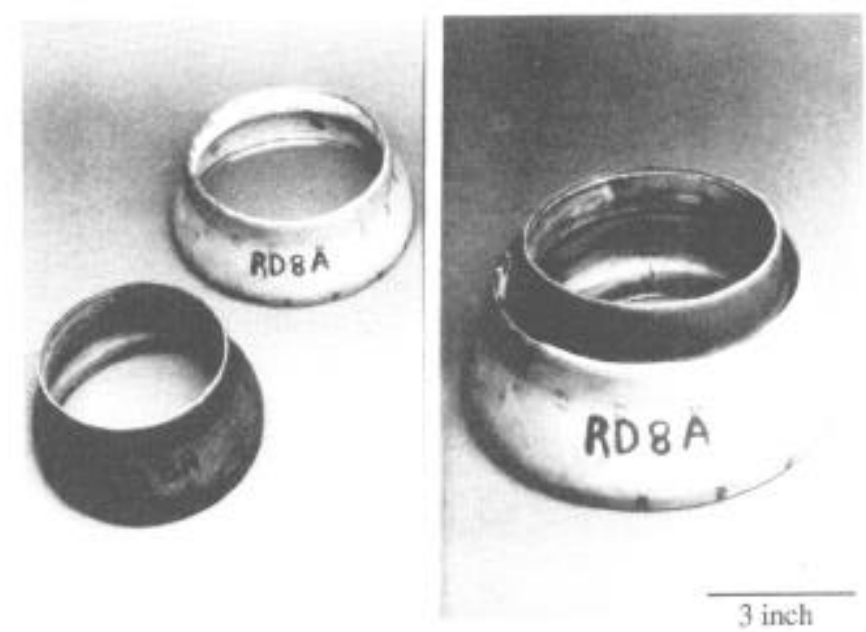

Figure 15(b). A transition duct made out of RD-8A. 


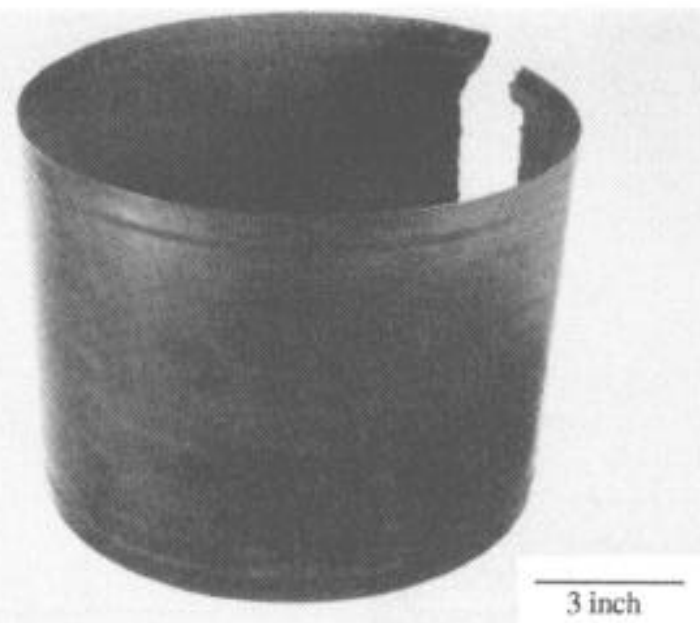

Figure 16(a). RD-8A F110 Exhaust Divergent Seal Face Sheet After Renovel from the Mandrel
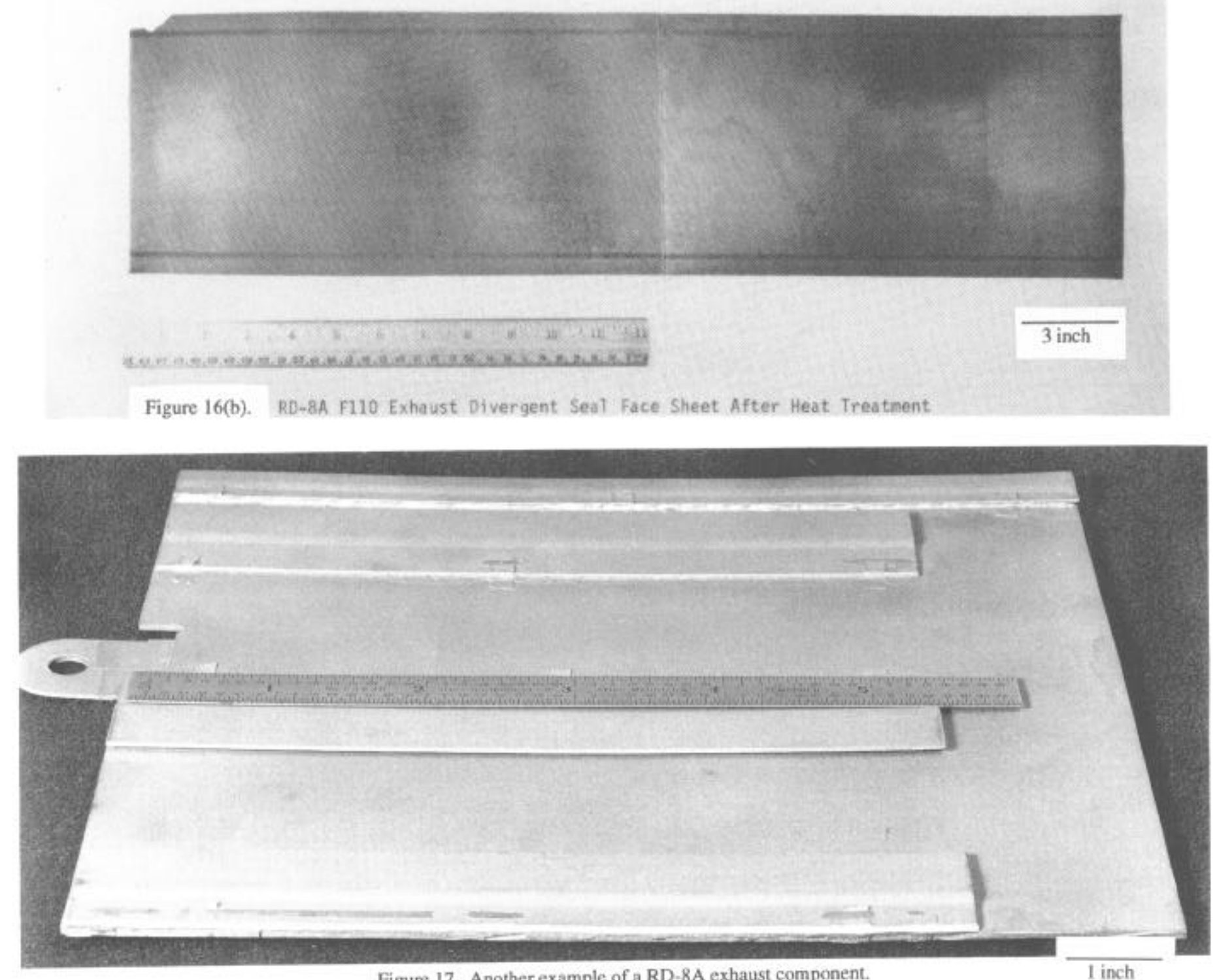

Figure 17. Another example of a RD-8A exhaust component. 